\title{
Veterinary Science and Agriculture.*
}

\section{By Dr. P. J. Du TorT.}

$\mathrm{T}$ HE prominent position which veterinary research occupies in the scientific life of South Africa to-day and the valuable practical results which have been obtained in this field of work have encouraged me to choose as the subject of my address the rôle which veterinary science plays in the agricultural development of a country. For obvious reasons my remarks will be confined almost exclusively to the live-stock side of agriculture in the wider sense ; and for equally obvious reasons most of my examples will be quoted from South Africa.

Since the beginning of the present century the growth of veterinary science has been remarkable. Indeed, it may be said that a new veterinary science has arisen unobserved by the general public. A quarter of a century ago the veterinarian was looked upon as a moderately useful though obscure member of the community, whereas to-day he is regarded as an essential factor in the economic machine of the State. In this transformation of veterinary science the British Dominions and Colonies played no unimportant part. The veterinarians who had migrated to those countries and taken with them the stock of knowledge which they had obtained at the European veterinary schools, found themselves confronted with new problems which required solution. Research work on a large scale became necessary. Novel methods of attacking disease had to be devised. The farmer soon came to realise that his very existence depended on the protective measures of the veterinary staffs.

I propose to review briefly some of the most notable achievements of veterinary science in recent years, and to indicate how the work of the veterinarian has become interrelated with that of workers in other branches of science.

\section{Antmal Diseases.}

Trypanosomiases.-Probably no other single group of disease-producing organisms has retarded the agricultural development of the continent of Africa more than that of the trypanosomes. If the cattle population of Africa be estimated at about 40 million head, it is quite safe to say that this number could easily be doubled if the danger of trypanosome infection were removed. In Nigeria, for example, only a portion of the drier northern provinces is suitable for cattle ranching ; the much more fertile southern provinces are practically devoid of cattle on account of the ravages of trypanosomiasis. Similar conditions obtain in almost every territory in Africa (except the extreme south). The soil is fertile, grazing is plentiful, the climatic conditions are favourable, but the presence of tsetse flies and trypanosomes renders cattle farming impossible.

Fortunately, we can record considerable progress in this field of work during recent years. The problem has been attacked along two lines mainly. A

* From the presidential address to Section M (Agriculture) of the British Association, delivered at Bristol on Sept. 8. direct attack has been launched against the parasite by means of drug treatment; and an indirect attack on the disease has been made through a campaign against the transmitter, the tsetse fly. The third line of attack, the immunisation of animals against infection, has not yielded very promising results.

One further trypanosome disease should be mentioned here, namely, dourine. Known for about a hundred and fifty years, this disease has been responsible for very heavy economic losses to horse breeders in Europe and other countries. With the aid of modern methods the disease was eradicated from most of the closely settled and well-organised western European States. But in the vast open spaces of Canada and other countries its eradication proved to be a much more difficult problem. It was only when Watson in Canada succeeded in perfecting a delicate diagnostic test for the detection of the infection that the eradication of the disease could be attempted seriously, and the results of the subsequent campaign in Canada have been entirely satisfactory. It should be added that Watson's success has stimulated further research into the problem of diagnosing other trypanosome infections by serological methods. A fair amount of success has attended these efforts and quite recently Robinson at Onderstepoort has reported further progress in the serological diagnosis of Trypanosoma congolense infection.

Piroplasmoses.-Under this heading are included diseases like redwater or Texas fever of cattle, biliary fever of dogs and horses, 'gallsickness' or anaplasmosis, and East Coast fever of cattle.

Their etiology was completely obscure until Theobald Smith and Kilborne in America, in a series of brilliant researches extending over the years 1888-92, succeeded in elucidating the nature of the first-named disease. Not only did these investigators discover the causal organism in the blood of infected cattle, but they also proved that the disease was transmitted by ticks and that the infection passed through the egg of the tick from one generation to the next. All this was completely new to science ; it was the first time that the transmission of a mammalian disease through an invertebrate host had been proved experimentally. This contribution to science by two veterinarians is worthy of special note.

In the case of redwater, great advances can be recorded. The direct method of attack is eminently satisfactory, thanks to the discovery by Nuttall and Hadwen in 1909 that the drug trypanblue has a specific action on the parasite of redwater of cattle and biliary fever of dogs. The treatment is so successful that the disease has lost much of its terror since the discovery of the value of this drug.

In the case of anaplasmosis, a method of immunisation has been practised in South Africa for nearly twenty years and has been the means of saving thousands of animals.

Of the diseases mentioned in this section, East

No. 3179, VoL. 126] 
Coast fever is the most formidable, because of the very high mortality attending it. This disease must have cost South Africa several million pounds since its first appearance nearly thirty years ago. The loss to the country has been partly direct through the death of many thousands of animals, partly indirect through the costly organisation which it is necessary to maintain to fight the disease.

It is impossible in this brief review to discuss the methods employed in the eradication of East Coast fever, or the many practical difficulties encountered in this campaign. For our purpose it is sufficient to state that the dipping of cattle in an arsenical bath has proved to be a very valuable aid in the fight against East Coast fever or any other tickborne disease.

In South Africa dipping has been practised since the beginning of this century, and has now become an integral portion of the daily routine of farming. No up-to-date stock farm can be found to-day without at least one dipping tank. Even if all the tick-borne diseases should now disappear, the majority of farmers in South Africa would continue to dip their animals regularly. The extent to which dipping is practised to-day may be gauged by the fact that there were in the Union of South Africa in 1929 more than 13,500 dipping tanks.

In the United States of America, where Texas fever (redwater) is the only serious tick-borne disease, an attempt is being made to eradicate completely the transmitter, Boophilus annulatus, by means of dipping. Large areas have already been cleared of these ticks, and the economic advantages to which these areas are entitled after being declared tick free, more than compensate for the expenses incurred.

Virus Diseases.-The vast sums of money which have been spent in Great Britain during the last few years on the eradication of foot-and-mouth disease should convince even the layman of the importance of this group of diseases.

In the olden days it was rinderpest which caused the severest losses. It has been calculated that the losses in Europe during the eighteenth century amounted to 200 million head of cattle. The disease made its appearance in England in 1865. A Royal Commission was appointed and its report is of value to this day. Later on, improved methods of eradication and prevention were evolved, and to-day most countries are free of rinderpest. However, in the Far East and in Central Africa the disease is still prevalent, and causes serious losses.

Two recent-outbreaks of rinderpest, one in Belgium in 1920 and the other in Australia in 1923, both of which were eradicated completely within a few months, have again shown how far veterinary science has advanced during the last century.

South Africa has been free of the two diseases just named for many years. But there are several other virus diseases which play a very important rôle. Among these, horsesickness and bluetongue of sheep are perhaps the most important. An extensive study of the former disease by Theiler and his co-workers has yielded some very valuable results, but the problem of horsesickness cannot be said to be solved. At present a method of immunisation with hyperimmune serum and virus is practised, and this method has given excellent results in mules. About 4000 mules are immunised annually, and it has been stated that if the Onderstepoort Laboratory had produced nothing else except this method of immunising mules, its existence would have been justified.

The second important virus disease of South Africa is bluetongue of sheep. The disease is of great economic importance and would have been a very serious hindrance to the sheep farmer had it not been for the fact that Theiler discovered a simple method of vaccination by means of which the losses from the disease can be reduced to a negligible quantity. Every year two to three million doses of this vaccine are issued to the farmers, and the ultimate saving to the country must be enormous.

Of the many other virus diseases of animals, only one more need be referred to here, namely, rabies. This most dreaded of all human and animal diseases has been eradicated from many countries, and is being kept out by strict quarantine measures. In 1918 the disease was introduced into England with a dog which had been smuggled in in an aeroplane. Strict measures were put into force and in a comparatively short space of time the disease was stamped out completely. Methods of preventive inoculation of dogs, in countries where the eradication of the disease is very difficult, have been tried on a large scale. The results have, on the whole, been very good; but it is too early to predict the future scope of these methods.

Bacterial Diseases.-Of the host of bacterial diseases, only a few need be mentioned here. The deadly glanders, which was known before the time of Christ, and even twenty-five years ago still caused severe losses amongst horses and constantly threatened the human population, has now been practically eradicated from all civilised countriesthanks to the accuracy of the diagnostic tests which are used to identify the disease.

Another disease which at one time was responsible for very serious losses and which has now practically disappeared is pleuro-pneumonia (lungsickness) of cattle. In the year 1860 about 187,000 head of cattle are stated to have died in Great Britain of this disease ; and the mortality in other European countries at that time was corresponding high. Towards the end of last century the disease was stamped out in Britain and to-day the greater part of Europe is free of the disease. South Africa, in spite of the fact that neighbouring countries are still infected, has been free of lungsickness since 1915 .

Only one other bacterial disease can be mentioned here, namely, tuberculosis. In 1901, Robert Koch, who about twenty years previously had discovered the cause of the disease, startled the scientific world by announcing to a Tuberculosis Congress in London that human tuberculosis and bovine tuberculosis were two distinct diseases which were not communicable from the one species to the other. Unfortunately, this statement proved to be wrong. We know to-day that human beings do contract bovine tuberculosis, and for this reason most

$$
\text { No. 3179, VoL. 126] }
$$


civilised countries adopt measures for the suppression of the disease in cattle. The United States and Canada are leading the world in this respect and have spent millions of pounds in compensation for the destruction of tuberculous reactors. Denmark, Germany, England, and other countries are also doing much and have achieved a large measure of success in their efforts to supply to the population milk and beef free of tubercle bacilli. But very much remains to be done. In human beings the mortality from tuberculosis is still high in all countries, and a considerable percentage of the deaths must be ascribed to the bovine strain of the organism. The disease in cattle can be stamped out provided enough money is made available.

Recently great interest has been shown in the attenuated strain of tubercle bacilli produced by Calmette and Guerin of the Pasteur Institute. Experiments in which it is attempted to immunise children and young animals, with this strain, are in progress throughout the world. It is sincerely hoped that all this work will prove that the method of Calmette and Guerin has given us yet another weapon against this insidious disease.

Internal Metazoan Parasites.-The only group that need be mentioned in this brief survey are the worms. These parasites have become more and more important and to-day they actually constitute the 'limiting factor' in successful sheep farming in many parts of the world. This subject forms a highly specialised science of its own, the science of helminthology - in which many notable successes have been achieved in recent years.

The ordinary stomach worm of sheep (Hamonchus contortus) is world-wide in its distribution and is the cause of very severe losses. Better farming methods will undoubtedly improve the position, but in the meantime farmers look to the veterinarian to rid their sheep of these deadly parasites. Various chemicals have been tried with varying degrees of success, but perhaps nowhere has the success been so marked as in South Africa, where, as a result of the researches of Theiler, Veglia, Green, and others, a method of treatment was recommended which has proved the salvation of many sheep farmers. The method consists of the accurate dosage of a mixture of arsenite of soda and copper sulphate; and the extent to which this method has been applied may be gauged from the fact that at present some 25 million doses of the mixture are issued annually from Onderstepoort. The method is not perfect, but it has been a great factor in making sheep farming a success where otherwise it would have been a dismal failure.

One further fact must be emphasised here. The menace of worm infection has become so great that no sheep farmer can hope to be successful if he disregards the teaching of modern science. Overstocking of farms must be prevented at all costs ; marshes must be drained or the sheep kept away from them; the sheep must be treated regularly according to the best methods known. If these precautions are adopted, the parasites can be kept in check and profitable sheep farming will become possible ; if the advice is ignored, then the financial loss to the farmer will be the smaller the sooner he gives up farming.

External Parasites. - The two most important groups of ecto-parasites, the ticks and the tsetse flies, have already been referred to.

A further very important group are the mites. These minute parasites are responsible for the diseases known as scab or mange in animals, and have caused untold losses. In the fight against these diseases the British Dominions have had very signal success. Australia and New Zealand have eradicated sheep scab completely, Canada is practically free of it, and in South Africa, where the presence of a large native population owning a very inferior class of sheep has made the campaign particularly difficult, the incidence of the disease has been reduced to infinitesimal proportions and complete eradication is hoped for within a short time.

Another very important ecto-parasite of sheep is the so-called blowfly. The trouble is caused by these flies depositing their eggs in the wool of sheep, especially in the soiled and moist parts, and by the resulting maggots causing serious damage to the wool and the sheep itself. The pest has assumed alarming proportions in Australia and is becoming more and more important in other countries, including South Africa. Determined efforts are being made to combat the pest and valuable progress has been achieved. In this research entomologists and veterinarians are working hand in hand.

Diseases due to Poisonous Plants.-That certain plants are poisonous and may have fatal effects when consumed by animals has probably been known for centuries. However, it is only during recent years that plants have been studied which produce diseases comparable with epizootic diseases. In this field of research South African workers have been prominent.

One of the most remarkable of these diseases is that known in South Africa as gousiekte (rapid disease) of sheep, which was studied some years ago by Thieler, Du Toit, and Mitchell. The cause of the disease was shown to be the plant Vangueria pygmoea. The poison contained in the plant acts on the heart muscle, causing a myocarditis with subsequent dilatation of the ventricles. As soon as the process has reached a certain stage the animal dies of 'heart failure'. To the casual observer the disease presents all the characteristics of an infectious disease.

Other no less remarkable diseases were studied by Theiler and his co-workers. A disease called geeldikkop (yellow thick head) in sheep was shown by Theiler (1928) to be due to a plant Tribulus terrestris, although more recent work by Quin, Steyn, and others at Onderstepoort has shown that there are other factors to be considered in the causation of this disease.

Vomiting disease of sheep was studied by Du Toit (1928) and proved to be caused by Geigeria spp. The disease may produce very severe losses in certain years, especially after droughts, when the plant is very widespread.

The study of poisonous plants is now being actively pursued in various countries, and further

$$
\text { No. 3179, VoL. 126] }
$$


interesting developments may be expected. It is obvious that the co-operation of botanists is essential for the success of this work.

Deficiency Diseases.-The great importance of the vitamins in the nutrition of human beings is so well known that it need not be stressed here. In the case of the common domestic animals (except perhaps the pig, the dog, and the fowl) the vitamins seem to be of far less importance than in human beings. On the other hand, mineral deficiencies are, generally speaking, much more important in animals than in human beings. In recent years it has been found that large portions of the earth's surface are deficient in some mineral or other essential for the normal health and growth of animals.

In South Africa, as well as in other African territories and in Australia, the most serious deficiency is that of phosphorus. Theiler and his co-workers have investigated the ill-effects of this deficiency on cattle very fully. They have shown that cattle grazing on phosphorus-deficient pastures develop a depraved appetite for bones and other carcase debris, and this may lead to the ingestion of toxic material with fatal results (lamsiekte in South Africa) ; further, that such cattle remain stunted in growth, are late in maturing, are frequently unfertile, produce very little milk, and are very susceptible to various diseases. By the addition of a small daily ration of phosphorus to the diet, they were able to bring about an almost miraculous improvement in the condition of the animals.

As a result of the general feeding of phosphorus compounds in the deficient areas of South Africa, the disease lamsiekte, which a dozen years ago caused enormous losses, has practically disappeared and cattle farming in those areas has again become profitable. The significant fact may be recorded here that the village of Vryburg in Bechuanaland, where ten years ago milk was very scarce, to-day owns a creamery which handles a larger volume of cream than any other creamery in South Africa.

\section{Other Veterinary Problems.}

Problems in connexion with the nutrition of animals are now receiving attention in many countries. The vast importance of correct feeding can be illustrated best by referring again to the phosphorus deficiency which exists in the pastures of South Africa and other countries. The astounding results which have been achieved with the addition of a small quantity of phosphorus compounds to the ration of the animals promise to revolutionise the beef and dairy industries.

Animal breeding also presents problems of great importance and these are intimately bound up with the problems of disease and nutrition. In South Africa, as in other countries, there is a constant cry for the replacement of the scrub bull by pedigree sires. This demand would be met to a far greater extent were it not for the fact that in many parts of the country pedigree bulls cannot live because of disease or nutritional difficulties.

In South Africa control over the diseases mentioned above is gradually improving and, in regard to the deficient areas, recent investigations by $\mathrm{Du}$
Toit and Bisschop have shown that the grading up of native stock can be carried out with complete success provided the deficient mineral is supplied. Both beef cattle and dairy cattle have been bred on the extremely deficient veld of Bechuanaland without signs of deterioration, and the cost of the supplementary ration has been negligible in comparison with the advantage derived from such feeding.

Gratifying though the success which has been achieved may be, the need for further research on live-stock problems has never been greater than it is to-day. The development of enormous areas in the British. Dominions and Colonies is entirely dependent on the progress of research. With the aid of further scientific measures, these new countries could absorb a very much larger population than they now harbour. Over-population will not make itself felt for generations, nor need over-production be contemplated seriously.

The prosperity of a very large percentage of the population, both European and native, in the Dominions and Colonies depends on the live stock industry - breeding of pedigree stock ; beef, mutton, or pork production; dairy farming; wool or mohair production; skin and hide trade; poultry farming, etc. These farmers look to the veterinary service of their countries more and more for assistance and protection. Without this assistance, profitable stock farming, especially in the tropical and subtropical countries, is impossible. The assistance, if it is to be effective, must be based on the latest achievements of scientific research. Rule-of-thumb methods will not suffice.

In a humble way South Africa has proved the wisdom of maintaining an adequate veterinary research service. At Onderstepoort the Government twenty-one years ago established what must be regarded as a fairly large research institute, if the size of the population be taken into consideration. This institute, under the brilliant directorship of Sir Arnold Theiler, soon proved to be not a liability but a valuable asset to the country. The results obtained in any one of its various sections would probably have justified the maintenance of the entire institution.

I have said that the Dominions and Colonies have played an important part in the recent growth and development of modern veterinary science. The quality of the research work produced by veterinarians in these countries has been of such high order that it soon placed veterinary science (which not many years ago was regarded as the Cinderella of sciences) abreast of the other sciences. As a matter of fact, in South Africa it can be said, without disparagement to any other group of workers, that veterinary science occupies a very high, if not the leading, position. This has had a wholesome influence on the science itself and on the type of worker who was recruited in its service. The stigma of inferiority which for so long was attached to the veterinarian has disappeared. To-day, veterinary science is looked upon as a field of work which offers almost unlimited scope for research and, in its practical application, may bring untold material benefit to a country.

$$
\text { Nc. 3179, VoL. 126] }
$$

